\title{
Gastronomy: An Opportunity for Malaysian Culinary Educators
}

\author{
Mohd Salehuddin Mohd Zahari \\ Faculty of Hotel and Tourism Management \\ UiTM Malaysia, Shah Alam, Selangor \\ E-mail: mohdsa02@salam.uitm.edu.my \\ Mohd Hairi Jalis \\ Faculty of Hotel and Tourism Management \\ UiTM Terengganu, Malaysia \\ E-mail: george_edz@yahoo.com \\ Muhammad Izzat Zulfifly \\ Faculty of Hotel and Tourism Management \\ UiTM Malaysia, Shah Alam, Selangor \\ E-mail: izzatzulkilfly@gmail.com \\ Salleh Mohd Radzi \\ Faculty of Hotel and Tourism Management \\ UiTM Malaysia, Shah Alam, Selangor \\ E-mail: sallehradzi@yahoo.com \\ Zulhan Othman \\ Faculty of Hotel and Tourism Management \\ UiTM Malaysia, Shah Alam, Selangor \\ E-mail: Zulhan@yahoo.com
}

\begin{abstract}
The word 'gastronomy' might sound peculiar for most people and even amongst 'culinarians'. Gastronomy is an understanding of various social, cultures, historical components, literature, philosophy, economic status, religion and others, in which food is the core subject. Meanwhile, gastronomy products refer to food and beverages as well as food-related activities of one's culture and heritage. Looking at the diversity of gastronomy and its development in the world today, there will be a promising need for well-prepared, dedicated chefs, administrators and managers in all areas including hotels, foodservice, food manufactures, catering, food media as well as other hospitality and tourism-related fields. This paper conceptualizes the relevancy of gastronomy in Malaysian culinary education.
\end{abstract}

Keywords: Gastronomy, Malaysia, Culinary Educator

\section{Introduction}

It is not wrong to say that the word 'gastronomy' has not been widely used and understood by most people in this country. This word in fact is still anomalous among 'culinarians' or foodservice personnel despite of their close association to the field of culinary. In that sense, it is therefore important to popularize and explain the definition of this word to Malaysian 'culinarians' as well as the public. In other words, the ways in which gastronomy relates to the local public, industry, education and training need to be explored. 
Etymologically, gastronomy is derived from the Greek word 'gastros' which means stomach, and 'nomos' which refers to knowledge or regulation. In actual fact, this term relates to food knowledge. Most dictionaries define gastronomy in terms of the art and science of good / delicate eating. This focuses on art and science, which translate in a particular sense as, skill and knowledge that neatly connect with the origins of the term. Gillespie (2000) looked at this term into two aspects which are practice and study. On the practical aspect, he refers gastronomy to the application of advice and guidance as well as the exercise of skills and knowledge, which together might be regarded as constituting an art of living. He contended that practical gastronomy has got something to do with the technique and standard involved in the conversion of raw produce into aesthetic, nationally, regionally and culturally-specific edible product. He further stated that the study of gastronomy is the understanding of the scope of production and preparation of food and drink as well as how, where, when and why they are consumed. It involves the philosophies, belief and values influencing gastronomic practices. This, in other words, relates to the social, cultural and historical aspect of food and eating, encompassing the study of cuisines, restaurants and dining, food and beverages, as well as tourism and gastronomy writing.

Despite of many other explanations and clarifications given to this term by several scholars (Santich, 1996, Long, 1998; Fileds, 2002; du Rand, Heat and Alberts, 2003), the definition drawn by Jean Anthelme Brillat-Savarin (1755-1826) was considered as the most relevant and appropriate. Directly quoted from Santich (2004, 2007), Savarin described that gastronomy does not specifically refer to the method by which food and beverage is produced, material component of food and beverages or even meal or cooking, but instead it covers the broader scope beyond simply what we eat (types of food) and in what form (implicating technology and method of cooking) to also include how we eat (hand, fork or chopstick), where we it (at the table, on the floor, standing or seated), when we eat (times/ period of eating the food ), why we eat ( motives disconnected with hunger) as well as with whom we eat (family or social networks).

According to Santich (2007), this broader meaning is gradually accepted. She summed up the term by stating that;

"Gastronomy not only relates to the production and preparation of food and drink and how, where, when, why people eats but more diversify. Gastronomy now entails an understanding of the various social, cultures, historical components, literature, philosophy, economic, religion and others with food as central axis"

Santich's in fact proposed an extensive multidisciplinary model for gastronomy study, drawing upon the natural and social sciences as well as the humanities which can be seen in figure 1. Despite a broad multidisciplinary and interdisciplinary approach of gastronomy study, this paper will not further elaborate on the disciplines, but instead it will only concentrate on the relationship between this term with the tourism, hospitality and culinary industry.

\section{Gastronomy in Tourism, Hospitality and Culinary and Foodservice Industry}

In the last three decades, people only associate tourism with travelling for pleasure and considers it as an industry (Kay, 2003), while some perceive it as merely providing services related to leisure and recreation (Michelitsch, 2001). Hunt and Layne (1991) acknowledged that those perceptions were mostly accepted until the late 70's. However, they were gradually changed in the mid 80's when people start looking at this industry in a broader realm. They described tourism as the activity of people taking trips away from home and the industry which has developed in response to this activity. Tourism is also viewed as a temporary movement of people to destinations away from their normal residential for leisure or recreation (Hankinson, 2005).

According to the World Tourism Organization (WTO, 1998), tourism comprises the activities of people travelling to and staying in places outside their usual environment for not more than one consecutive year for leisure, business and other purposes not related to the exercise of an activity remunerated from within the place visited. Baker (1995) and Leiper (2003) summarized tourism as an activity that involves staying at a hotel or resort (accommodation), shopping or mountain climbing (recreational and leisure), cruising (transportation), as well as attending meetings and conferences (business). Hall (2003) and Kay (2003) elaborated that tourism activity encompasses of various sectors such as accommodation, leisure, recreation, sports, culture, transportation, business as well as including food and beverages.

Goeldner and Ritchie (2006) asserted tourism as the process, activity and outcome arising from the relationships and interactions among tourists, tourism suppliers, host governments, communities and surrounding environments. In recent years, tourism activities also involve travelling to areas of natural or ecological interest for the purpose of observing wildlife and learning about the environment as wild life ecotourism (Cho, 1998), appreciating the deep time of landscapes as geo-tourism (Hose, 2005), as well as traveling through legacy as heritage tourism and contemporary recreation as transport tourism (Hall, 2005). In sum, all these types of tourism activities produced different kinds of experiences (Long, 2004).

Besides the above notion, Goeldner and Ritchie (2006) stated that food and beverages cannot be ignored by tourists, and some in fact consider them as one of the most important elements when they are on the travelling mood. Richards (2002) contended that besides experiencing various tourism activities, tourists without a doubt will encounter various types of food and beverages in the visited country. In other words, during the period of vacation, tourists will also 
experience and consume varieties of food and beverages, as well as learn the food culture and heritage of that particular country. They also consider all these food and beverages as well as food-related activities as part of gastronomy products (Santich, 1996; Hall and Mitchell, 2005).

According to Pine and Gilmore (1999), the basis of the economy now is slightly shifting from the delivering services to staging experiences. Food and beverage, besides accommodation and other tourism activities, are considered as one of the most important elements in the tourism and hospitality industry today. The various types of food and beverages are also viewed as an integral component of a travel experience. In other words, the quality of the basic elements of the tourism products will increasingly be experienced by tourists, and these include food and beverages, food culture practices and food heritage.

This is because food and beverages structure the tourists' day and a large proportion of tourists experiences are spent either consuming food and drink or deciding what and where to eat. Good food promotion and campaigns without a doubt is an important element in promoting popular holiday destinations and influencing tourists' destination choices (Gursoy and McCleary, 2004). In fact, many commentators contended that it is crucial for the tourism marketers to develop or to find ways to add value to make the tourists' eating experience lasting and memorable (Fileds, 2002; du Rand, Heat and Alberts, 2003; Sampaio, 1985).

Long (2004) used the term 'gastronomic tourism' to express the idea of experiencing food and beverages (wine) and other cultures related to them. Wolf (2002) argued that gastronomic tourism encourages the pursuit of travel in the quest for the enjoyment of prepared food, drinks and other related food activities; resulting in a great memorable gastronomic experience. This statement clearly suggests that gastronomic products not only focus on food but also beverages that reflect one's culture and heritage. This supports the earlier work by Finkelstein (1989) and Mennel, Murcott and Van Otterloo (1992), which noted that culinary and dining experiences when one is on holiday is often relived and retold to a wider non-traveling audience. These experiences have the power to modify eating and drinking habits, tastes as well as imbue the tourists' cultural experiences of the peoples of the new locations and countries being visited (Johns and Clarke, 2001; Johns and Kivela, 2001).

Kivela and Crotts (2006) explained that seasoned tourists attach great value to the gastronomic and culinary experience of the countries being visited, and that these go hand in hand with the social and cultural attractions being experienced. In fact, they argue that gastronomic products play a pivotal role in marketing some tourism destinations. Some travel organizations regularly offer gourmet or culinary holidays, with Italy and France leading the rank as top destinations as well as countries in Asia (Intrepid Travel, 2004). Kivela and Crotts (2006) reported that holiday with cooking and wine appreciation feature regularly in destinations like Tuscany and Provence in Europe, Melbourne and the Sydney Napa Valley in Australia as well as the Sonoma Valley in California. These places in fact have become premier food and wine tourism destinations.

Kivela and Chu (2001) noted that tourists not only dine out in the search of new tastes in the choice of food and beverages, but at the same time are also on the lookout for new gastronomic experiences when visiting a country. In relation to this statement, the Intrepid Travel Agency (2004) reported that tourism and holiday operators from Australia, the United States, many Europe and Asian countries like China, India, Thailand, Malaysia, Vietnam and Japan now offer gastronomy tour packages, which combine shopping with side-trips to sample the indigenous food and beverages (wine) available. This tour agency recognizes Asian countries for its delicious cuisines, and travelers on their trips make the most of this aspect while exploring these countries' traditional tourism offerings.

Scarpato (2002) noted that gastronomy satisfies all conventional ingredients that make up a cultural tourism product. It is an additional factor that is over and above the traditional ingredients that make up a holiday - sun, sea and sand. He added that gastronomy can add value to the traditional tourism experience; especially for those who yearn for more and are constantly searching for new products and experiences.

The development of gastronomic experiences is strongly evident in the appearance of restaurants that offer a total package comprising of food, entertainment and atmosphere. In some European countries, notably France and Italy, gastronomy is also considered as a principal resource. In a study of visitor and non-visitor images of Mediterranean destinations, Italy was found to score significantly higher on 'appealing local food (cuisine) than Turkey, Egypt or Greece' (Baloglu and McCleary, 1999). Boyne, Wiliams and Hall (2002) as well as Jones and Jenkins (2002) demonstrated how food has been used as a vehicle to reposition Scotland and Wales. Both have developed similar marketing programs: 'A Taste of Scotland' and 'A Taste of Wales'. The Taste of Scotland initiative created a marketing scheme in which participating establishments would agree to provide dishes which were either 'traditional or using recognizably Scottish produce, to provide the visitor with a meal of Scottish food' (Hughes, 1995). Hughes argued that the Taste of Scotland scheme constructed a food heritage for Scotland, which could then be used as an important marketing tool. Similar schemes are evident in other areas as well. In the Alto Minho region of Portugal, for example, a recipe book was produced by the regional tourist board to give visitors the opportunity to 'carry away with (them) an enduring memory of the tastes and pleasures of dining in the lands of Minho' (Sampaio, 1985). 
Gastronomy is also becoming the driving force behind the revival of tourism for destinations that are struggling for one reason or another. For example, Croatia faced a Herculean task in rebuilding its tourism industry after the civil war that broke up Yugoslavia from the year 1990 to 1995. To this day, an integral part of its rebuilding program strongly features local foods, regional cuisines, wine-making and food customs. Similar examples can be drawn from countries such as Vietnam and Kampuchea (now known as Cambodia). It seems that when dining out at a destination, tourists in effect consume "ingredients" that satisfy their feelings and enhance their cultural experiences (Fields, 2002).

For whatever reason, the above notion explicitly signifies that gastronomy is not only relevant to the tourism, hospitality and culinary industry, but also to the study of gastronomy which is significantly important or extremely relevant particularly among the culinary educators.

\section{Gastronomy and Malaysian Culinary Education}

Based on informal discussions with experts from various sub-sectors of the food industry like chefs, hotel managers, catering managers, food manufacturers and educators, Malaysian foodservice and culinary world is believed to be more complicated and complex with broader perspectives. The need for well-prepared and dedicated administrators and managers in all areas including hotels, foodservice, and food manufactures, catering and media is growing stronger. Career as a chef will not only function as it always should be, but instead they will be well-accepted in all realms of food and other related hospitality and tourism field. They further contended that this particular career will be more challenging in the near future, and chefs with business skills and food technology will be the most sought after candidates to fill positions in various job markets. This is particularly true as the diverse field of gastronomy offers related career opportunities such as Research and Development personnel in food processing plant and even as specialists in the area of food marketing, food writing, human resource and food connoisseur.

From the above statement, it is therefore extremely essential for today's chef to have an array of skills and to be knowledgeable in the area of food science, food technology, food consumption and application which are classified under the field of gastronomy in responding to the industry needs. Besides that, the ability to think analytically and critically in any given situations or problems is another quality that a future professional 'culinarian' should possess in order to be competent in the challenging industry situation. Graduates with all these excellent traits without a doubt could be the future professionals and leaders in related industries such as hospitality, manufactures, education, media and tourism.

Looking at the diversity of gastronomy field and its opportunities, there is no reason why institutions or culinary educators should not introduce various useful programs, as such learning could benefit the industry and the graduates as well. Moreover, culinary is a small part of gastronomy, and in order to meet the future challenges, the culinary educators should go for a broader scope of gastronomy. In this case, several universities in the USA, Italy, France and Australia such as Boston University Metropolitan College, the University of Bologna and University of Adelaide have taken a bold initiative in introducing programs and courses in gastronomy. In pursuing this promising pace and development, Universiti Teknologi MARA (UiTM), through the Faculty of Hotel and Tourism Management, has also taken huge strides by introducing its own Master in Gastronomy Management. UiTM's efforts and decisions are proven to be timely in respond to the industry needs, and at the same time will definitely help the students to obtain better career prospects in the future.

Nonetheless, the development of gastronomy study in Malaysia is still a long way to go. Thus, all the institutions or culinary educators in Malaysia are urged to offer or introduce gastronomical programs and courses which can be valuable for culinary students and the industry as well. Educators must also strengthen their relationship with the industry to ensure that the benefits to both students and industry from the educational process can be maximized. Failure to develop such a commonality of approach leads to the question "Why should institutions introduce new programs if the industry itself does not want the graduates?"

\section{References}

Baker, V. (1995). Leisure and tourism ( $2^{\text {nd }}$ Ed.). London: Longman Group Ltd.

Baloglu, S. and McCleary, K.W. (1999). U.S. international pleasure travelers' images of four Mediterranean destinations: a comparison of visitors and non-visitors. Journal of Travel Research, 8 (38), 144-152.

Boyne, S., Wiliams, F. and Hall, D. (2002). On the trail of regional success: tourism, food production and Isle of Arran taste trail. London: Routledge.

Cho, B. (1998). Assessing tourist satisfaction. Tourism Recreation Research, 1 (23), 47-54.

du Rand,G., Heath, E. and Alberts, N. (2003). The role of local and regional food in destination marketing: a South African situation analysis. Journal of travel and tourism marketing, 3 (17), 97-112.

Fields, K. (2002). Demand for the gastronomy tourism product: Motivational factors. London: Routledge. 
Finkelstein, J. (1989). Dining out: A sociology of modern manners. Cambridge: Polity.

Gillespie, C. (2002). European Gastronomy into the 21st Century. Oxford: Butterworth-Heinemann, Oxford.

Goeldner, C. R.and Ritchies, B. J. (2006). Tourism: Principles, practices and philosophies (10 ${ }^{\text {th }}$ Ed.). New Jersey: John Wiley and Sons, Inc.

Gursoy, D. and McCleary, K. (2004). An integrated model of tourists' information searches behavior. Journal of tourism research, 5 (31), 353-373.

Hall, C. M. (2003). Introduction to tourism dimensions and issues (4 ${ }^{\text {th }}$ Ed.). Sydney: Hospitality Press.

Hall, C. M. and Mitchell, R. (2005) Gastronomic tourism: Comparing food and wine tourism experinces. In Novelli, M. (Eds.), Niche tourism: contemporary issues, trends and cases (pp. 89-100). Boston: Elsevier Butterworth Heinemann.

Hall, D. (2005). Transport tourism: Travelling Through heritage and contemporary recreation. In Novelli, M. (Eds.), Niche tourism: contemporary issues, trends and cases (pp. 89-100). Boston: Elsevier Butterworth Heinemann.

Hankinson, K. (2005). Consumer culture and modernity. Cambridge: Polity Press.

Hose, T. A. (2005). Geotourism: Appreciating the deep time of landscapes. In Novelli, M. (Eds.), Niche tourism: contemporary issues, trends and cases (pp. 89-100). Boston: Elsevier Butterworth Heinemann.

Hughes, G. (1995). Food, tourism and Scottish heritage, in D. Lesie (ed.) Tourism and leisure-culture, heritage and participation. Britghton:LSA.

Hunt, M. and Layne, S. (1991). Eating out: Social differentiation, consumption and pleasure. Cambridge: Cambridge University Press.

Intrepid Travel. (2004). Intrepid gourmet traveller. Melbourne: Author.

Johns, N. and Clarke, V. (2001). Mythology analysis of boating tourism. Journal of Tourism Research, 28 (2), $334-359$.

Johns, N. and Kivela, J. (2001). Perceptions of the first time restaurant customer. Journal of Foodservice Technology, 1 (1), 5-11.

Jones, A. and Jenkins, I. (2002). A taste of Wales-Blas Ar Gymru: institutional mailaise in promoting Welsh food tourism products. London: Routledge.

Kay, H. K. (2003). Selling Tourism. New York: Thomson Ltd.

Kivela, J. and Chu, C. Y. H. (2001). Delivering quality service: Diagnosing favourable and unfavourable service encounter in restaurants. Journal of Hospitality and Tourism Research, 25 (3), 257-271.

Kivela, J. and Crotts, R. (2006). Tourism and gastronomy: gastronomy's influence on how tourists experience a destination. Journal of Hospitality and Tourism, 3 (30), 354-377.

Leiper, N. (2003). Introduction to tourism. In tourism management. New York: Hospitality Press Pearson.

Long, L. M. (2004). Culinary Tourism. Lexington: University Press of Kentucky.

McIntosh, R. W., Goeldner, C. R. and Ritchie, J. R. (1995). Tourism: Principles, Practices, and Philosophies (7 ${ }^{\text {th }}$ Ed.). New Jersey: John Wiley and Sons, Inc.

Mennel, S., Murcott, A. and Van Otterloo, A. H. (1992). The sociology of food: Eating, diet and culture. London: Sage.

Michelitsch, G. (2001). Consumption, food and taste: Culinary antinomies and commodity culture. London: Sage.

Richards, G. (2002). Gastronomy: an essential ingredient in tourism production and consumption? London: Routledge.

Sampaio, F. (1985). The good food of the upper Minho: Tourism and culture attraction. London: Sage.

Santich, B. (1996). Sustaining Gastronomy. In: Proceedings of the Eighth Symposium on Australian Gastronomy: Sustaining Gastronomy, Adelaide, 28-30 September, 1994.

Santich, B. (2004). The study of gastronomy and its relevance to hospitality education and training. International Journal of Hospitality Management, 23 (1) 15-24.

Santich, B. (2007). The study of gastronomy: A catalyst cultural understanding. The International Journal of the Humanities, 5 (6),

Scarpato, R. (2002). Gastronomy as a tourist product: The perspective of gastronomy studies. London: Routledge.

Wolf, E. (2002). Culinary tourism: A tasty economic proposition. Retrieved in June 25, 2007, from http://www.culinarytourism.org.

World Tourism Organization (1998). Market research-Text and cases. New York: Haworth Press. 


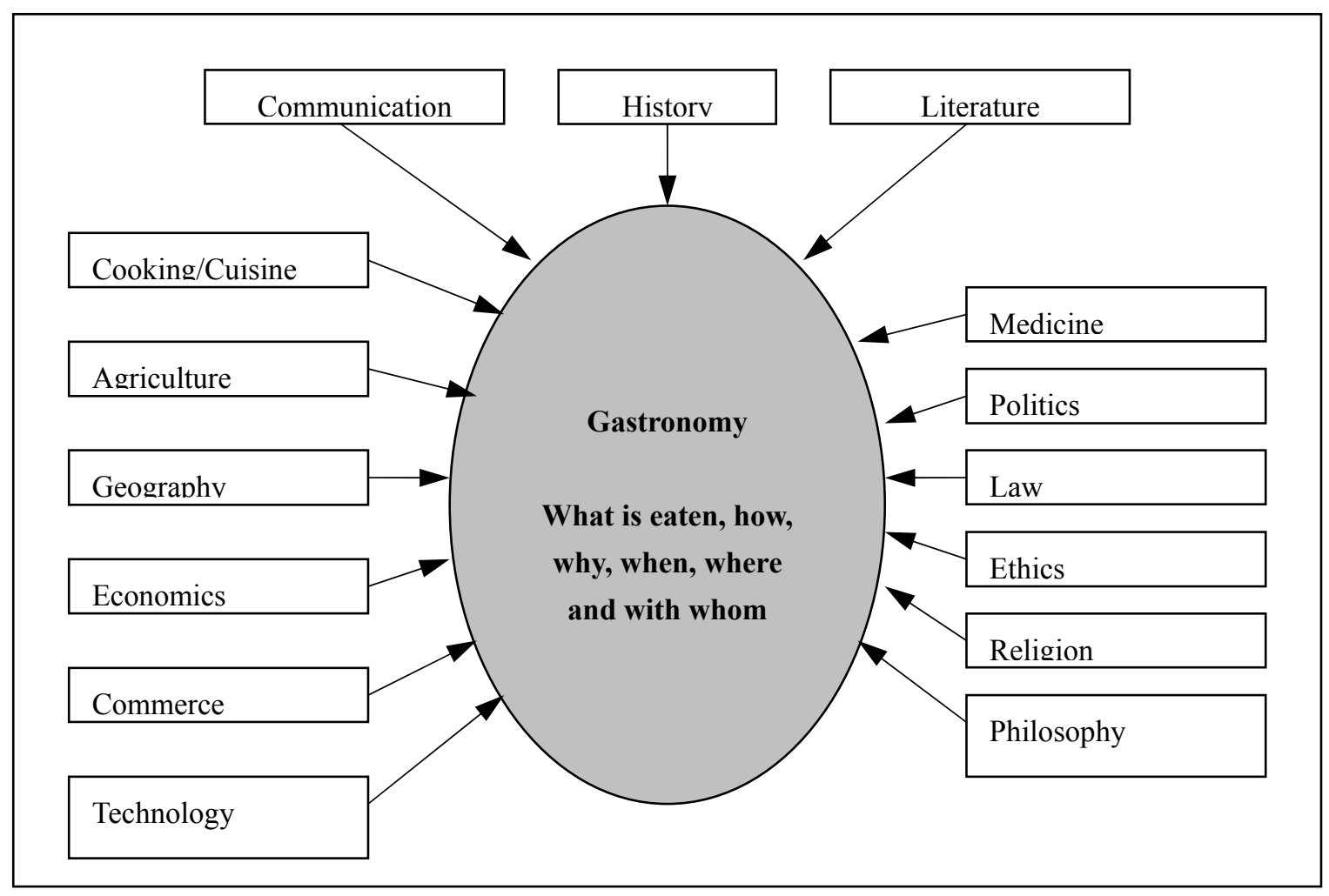

Figure 1. Multidisciplinary Model for the study of Gastronomy (Santich, 2007) 